\section{Addressing stigma and discrimination in the Covid- 19 pandemic: a public health ethics issue}

Published online first on November 29, 2021. DOI: 10.20529/

IJME.2021.092

Keywords: Stigma; discrimination; Covid-19, public health, misinformation

The Covid-19 pandemic continues to stalk the globe, ever since the first outbreak in December 2019. Variants of concern and fear of subsequent pandemic waves continue to challenge every nation. The virus has caught communities off-guard many times with grave consequences.

The scale of the pandemic initially led to unprecedented measures, including widespread lockdowns and travel restrictions, social distancing measures and isolation of infected individuals. The disruption of normal life with the emphasis on exclusionary measures resulted in misinformation, fear, mistrust and stigma in the community (1). The consequent discrimination against the susceptible was against all norms of public health ethics which seek to secure adequate health for all and to minimise inequalities. Stigmatisation, leading to delay in treatment-seeking and aggravating disease transmission, yields poor health outcomes (2).

Furthermore, health-related stigma exacerbates pre-existing divisions in communities such as race, gender, religion, and class $(3,4)$. In the Covid-19 pandemic, people of Asian descent around the world have been subjected to racist attacks, significantly affecting their health and livelihoods (5). Public health measures that do not take into account these effects, add to the problem, by disproportionally affecting disadvantaged groups eg transport and visa restrictions, or denial of employment or housing. All these are causes of severe distress.

The current pandemic differs from its predecessors in the sheer flow of unregulated information, marked by conspiracy theories and inaccurate medical information (6). However, the accessibility and penetration of technology can be used for targeted messaging to avoid stigmatising patients or groups of patients.

Heijinder and Van Der Meij have described multiple levels of interventions against stigma: at the intrapersonal, interpersonal, organisational and community levels (7). All of these can be utilised to plan interventions to address stigma and discrimination in the current pandemic.

\section{- Intrapersonal/individual level}

These interventions aim to improve knowledge and empower individuals to make the right decisions about how to seek care, protect themselves, avoid panic, and to encourage them to share their experiences and lend support to other patients. Social media platforms can be harnessed to create a positive narrative that the disease can be overcome; and to help dispel myths in the community.

\section{- Interpersonal level}

These interventions target the patients' environment and should aim to inform and support the families, neighbourhoods, and work environment of affected individuals. Home care teams may be constituted with local individuals, non-governmental organisations, and self-help groups as members.

\section{- Organisational/institutional level}

Stigma against essential workers should be recognised and addressed through legal measures if necessary, while lauding their efforts. Frontline workers must also be trained to avoid criminalising at-risk individuals while enforcing quarantine and lockdown measures.

Guidelines and protocols to support affected individuals and measures to protect their livelihoods during and after the pandemic must be drafted and implemented. The misuse of power imbalances between civilians and the state must be dealt with firmly.

\section{- Community level}

Community participation is an essential tool in managing public health disasters (1). Popular opinion leaders' support to tackle stereotypes and prejudice, and provide advocacy for frontline and public health workers will facilitate this.

Multilevel interventions for neutralising stigma need to be adopted early in the outbreak. The stigmatised must not be treated as mere victims and should be integrated into mitigation efforts. Existing frameworks must be utilised to plan interventions, promote trust, and dispel fears and myths, to control the pandemic.

Suneela Garg, (gargsuneela@gmail.com), Director Professor HAG and former Head, Department of Community Medicine, Maulana Azad Medical College, New Delhi 110 002, INDIA, and Advisor ICMR Member Task Force DBT; Anjali Rajeev (anjali0804@gmail.com), Post-Graduate Resident, Department of Community Medicine, Maulana Azad Medical College New Delhi 110 002; Nidhi Bhatnagar (corresponding author bhatnagarnidhi.mamc@gmail.com), Associate Professor, Department of Community Medicine, Maulana Azad Medical College, New Delhi 110 002, INDIA. 


\section{References}

1. Kickbusch I, Reddy KS. Community matters - why outbreak responses need to integrate health promotion. Glob Health Promot. 2016 Mar;23(1):75-8.

2. Fokunang CN, Tembe-Fokunang EA, Awah P, Djuidje Ngounoue $M$, Chi. PC, et al. The Role of Ethics in Public Health Clinical Research. In: Current Topics in Public Health. InTech Open Book Series Open Book Series; 2013 [cited 2020 Dec 8]. Available from: http://dx.doi.org/ $10.5772 / 52478$

3. Weiss MG, Ramakrishna J. Stigma interventions and research for international health Lancet 2006 Feb 11:367(9509):536-8.

4. Goffman E. Stigma: Notes on the Management of Spoiled Identity. New York: Simon and Schuster; 2009.

5. Stop the coronavirus stigma now. Nature 2020 Apr;580 (7802):165.

6. Barrett R, Brown PJ. Stigma in the Time of Influenza: Social and Institutional Responses to Pandemic Emergencies. J Infect Dis. 2008 Feb 15;197 Suppl 1:S34-S72.

7. Heijnders M, Van Der Meij S. The fight against stigma: an overview of stigma-reduction strategies and interventions. Psychol Health Med. 2006 Aug;11(3):353-63. 